\title{
Joint Nordic prospective study on human herpesvirus 8 and multiple myeloma risk
}

\author{
R Tedeschi', T Luostarinen ${ }^{2}$, P De Paoli', RE Gislefoss ${ }^{3}$, L Tenkanen ${ }^{4}$, J Virtamo ${ }^{5}$, P Koskela $^{6}$, G Hallmans $^{7}$, \\ M Lehtinen ${ }^{6}$ and J Dillner*,8 \\ 'Department of Microbiology-Immunology and Virology, Centro di Riferimento Oncologico, IRCCS, I-3308I Aviano, Italy; ${ }^{2}$ Finnish Cancer Registry, Institute \\ for Statistical Epidemiological Cancer Research, FIN-00 I 7 I Helsinki, Finland; ${ }^{3}$ Institute of Clinical Biochemistry, Rikshospitalet, 0027 Oslo, Norway; \\ ${ }^{4}$ Helsinki Heart Study, National Public Health Institute, Helsinki, Finland; ${ }^{5}$ Department of Epidemiology and Health Promotion, National Public Health \\ Institute, Helsinki, Finland; ${ }^{6}$ Department of Viral Diseases and Immunology, National Public Health Institute, Oulu, Finland; ${ }^{7}$ Northern Sweden Health and \\ Disease Study, The Medical Biobank, Umeå University, Sweden; ${ }^{8}$ Department of Medical Microbiology, Lund University, University Hospital MAS, \\ Entrance 78, S-20502 Malmö, Sweden
}

An association between human herpesvirus 8 (HHV8) and multiple myeloma (MM) has been reported, though most studies have not confirmed such association. To follow-up on a previous prospective seroepidemiological study, where HHV8 tended to associate with MM risk, we linked five large serum banks in the Nordic countries with the Nordic cancer registries and 329 prospectively occurring cases of MM were identified, together with I63I control subjects matched by age and gender. The HHV8 seroprevalences among cases and controls were similar (12 and 15\%, respectively) and HHV8 seropositivity did not associate with the risk of MM, neither when considering positivity for lytic antibodies (relative risk $(R R)=0.8,95 \%$ confidence interval $(C l)=0.5-1.1$ ) nor for latent antibodies $(R R=0.6,95 \% \mathrm{Cl}=0.1-2.7)$. Similar risks were seen when analysis was restricted to case-control sets with at least 2 years lag before diagnosis $(R R=0.8,95 \% \mathrm{Cl}=0.5-1.2$ and $R R=0.9,95 \% \mathrm{Cl}=0.1-4.2)$. In conclusion, the data indicate that $\mathrm{HHV} 8$ infection is not associated with MM.

British Journal of Cancer (2005) 93, 834-837. doi:10.1038/sj.bjc.660275 I www.bjcancer.com

Published online 30 August 2005

(c) 2005 Cancer Research UK

Keywords: immunofluorescence; biobank; multiple myeloma; HHV8; nested case-control study

Rettig et al (1997) reported that HHV8 DNA was present in bone marrow dendritic cells of multiple myeloma (MM) patients, but subsequent studies had inconsistent findings (Olsen et al, 1998; Beksac et al, 2001; Patel et al, 2001; Hermouet et al, 2003). Several studies found that HHV8 antibodies did not associate with MM (MacKenzie et al, 1997; Masood et al, 1997; Parravicini et al, 1997; Bouscary et al, 1998; Perna et al, 1998; Santarelli et al, 1998; Ablashi et al, 2000), although one study found an association (Gao et al, 1998). However, the large amounts of myeloma proteins in MM patients' sera may induce systematic measurement biases in serological assays. We previously studied $\mathrm{MM}$ in a prospective study nested in a cohort of 39057 healthy Finnish subjects (Tedeschi et al, 2001a). Seropositivity for lytic and latent HHV8 antigens was found in 16 and $0.4 \%$ of the population, and had a nonsignificant tendency to associate with $\mathrm{MM}$ risk (relative risk $(\mathrm{RR})=2.02,95 \%$ confidence interval $(\mathrm{CI})=0.94-4.33$ and $\mathrm{RR}=10.00,95 \%$ $\mathrm{CI}=0.91-110.29$, respectively), but the statistical power of our study was limited. We have therefore performed a new study with the same study design and HHV8 analyses, but on an independent and much larger material.

*Correspondence: Professor J Dillner; E-mail: joakim.dillner@med.lu.se Received 3 May 2005; revised 22 July 2005; accepted 22 July 2005; published online 30 August 2005

\section{MATERIALS AND METHODS}

\section{Cohorts}

The study base was constituted of five prospectively followed cohorts covering about 1133000 individuals who had donated serum and/or plasma samples.

The Finnish Maternity Cohort contains serum samples from 700000 pregnant women attending maternity clinics (about $98 \%$ of all those pregnant since 1983) in Finland for serological screening of rubella immunity, HIV and hepatitis in week 14 of pregnancy (Kibur et al, 2000).

The Helsinki Heart Study tested whether treatment with gemfibrozil (a fibric acid derivative) reduces the incidence of coronary heart disease (CHD) in middle-aged, dyslipidaemic men, the volunteers for which were selected from men aged 40-55 years, employed by two government agencies and five industrial companies, and living in different parts of Finland. About 19000 men were enrolled, during 1980-1982.

The Alpha-Tocopherol, Beta-Carotene Cancer Prevention (ATBC) Study evaluated whether daily supplementation with alphatocopherol or beta-carotene would reduce the incidence of lung cancer and other cancers (ATBC Cancer Prevention Study Group, 1994).

The Janus project was started in 1973 to collect and store blood samples from healthy persons for later scientific use. Serum samples from population-based invitational health examinations from the whole Norway and from the Red Cross blood donors in 
capital Oslo and surrounding areas are included in the biobank, which now covers about 315000 persons, $10 \%$ of whom are blood donors who give $20 \mathrm{ml}$ of extra blood every other year to the Janus project. At the first donation a declaration of consent is signed, allowing use of the sera for anonymous cancer research.

The Northern Sweden Health and Disease Study includes three major subcohorts, including the subcohort from an intervention project that invites all individuals resident in the Västerbotten county of Northern Sweden aged 40, 50 and 60 (during 1985-1995, also those aged 30 ) for a health-promoting visit and to donate a blood sample (fractionated into plasma, erythrocytes and buffycoat, all stored at $-80^{\circ} \mathrm{C}$ ) for later research purposes. The project started in 1985 and currently includes about 70000 individuals.

\section{Identification of cases and controls}

A total of 329 prospectively occurring cases of MM were identified in the Nordic joint study base, all diagnosed more than a month after the serum sampling. Five control subjects that had not developed MM during and with equal length of follow-up were matched to each case for biobank, sex, age at serum sampling $( \pm 2$ years), time of withdrawal of serum sample ( \pm 2 months) - and in Norway also for county of residence - and were selected at random among all eligible controls. If controls could not be found, the matching criteria were widened in successive steps of \pm 1 year of age and \pm 1 month of storage until controls were found. The maximum age difference between a case and any matching controls at the serum sampling was 2.1 years and the mean age difference was 0.9 years (standard deviation 0.6 years). The date of serum sampling differed on average by 0.9 months between a case and its controls (standard deviation 0.8 months). The samples were analysed in batches, each containing max 54 samples (typically containing nine cases and their 45 matched controls), with the sample order assigned randomly. The record of randomisation contained an 8-9-digit number consisting of biobank code (one digit), running number (3-4 digits), batch number (two digits), and location within the batch (two digits).

All serum samples were sent frozen for laboratory analysis at the Centro di Riferimento Oncologico in Aviano, Italy, where they were analysed by immunofluorescence for the presence of HHV8 antibodies by experienced laboratory personnel. The analysing laboratory was blinded to all and any information about the sample. In all, 120 serum samples from the Helsinki Heart Study, 185 serum samples from the Finnish Maternity Cohort, 258 plasma samples from the Västerbotten study, 179 serum samples from the ATBC Study from Finland and 1218 serum samples from the Janus project in Norway were assessed. Samples from 11 cases and 52 controls in the Helsinki Heart Study had accidentally been subjected to an additional freeze-thawing cycle.

\section{Laboratory methods}

HHV8 antibodies were determined using mouse monoclonal antibody enhanced immunofluorescence assay (mIFA) (Lennette et al, 1996) using the BCBL-1 cell line, as described elsewhere (Tedeschi et al,2001a). Specimens were screened at a 1/10 dilution and positive samples were titrated up to $1 / 640$. The samples were always analysed in batches of up to 54 samples derived from the same biobank. Each batch was tested together with positive (from HHV8-positive Italian KS patients) and negative (healthy HHV-8 negative donors) serum controls. All samples were also tested with a negative control cell line (Ramos, Burkitt lymphoma cells) and sera reacting with Ramos cells were scored as not analysable.

In all, 376 serum samples ( $94 \mathrm{MM}$ cases and 282 controls) were also assessed for HHV8 DNA using a sensitive real-time (TaqMan) PCR assay (Heid et al, 1996) that amplifies a $67 \mathrm{bp}$ amplicon in the HHV8 minor capsid protein gene (open reading frame 26). DNA was extracted using the QiAmp Blood Kit (Qiagen Gmbh, Hilden,
Germany) from $50 \mu$ l serum into $50 \mu$ l distilled water. The number of genome equivalents in each sample was calculated from an EBV DNA standard (Enbom et al, 2001). The standard curve was created using the ABI PRISM 7900 Sequence Detection System software (2.1.1v, Applied Biosystems, Foster City, CA, USA), by plotting the $C_{\mathrm{t}}$ values against each known concentration of the EBV standard. Reaction conditions were as reported previously (Tedeschi et al, 2001b). Negative control water samples (for EBV and for HHV8), positive control HHV8 DNA extracted from culture supernatant of the BCBL1 cells and negative control from the serum sample of an HHV8 seronegative healthy donor were included in triplicate on each plate. The samples were analysed in triplicates, including one inhibition control to which $0.5 \mu \mathrm{l}$ of the positive control was added to control for inhibitory substances in the samples.

\section{Statistical analysis}

The laboratory results were transmitted to the Finnish Cancer Registry, where the code was broken and the RR of developing MM given HHV8 seropositivity was estimated by exact conditional logistic regression with LogXact 5 software (Cytel Software Corporation, Cambridge, MA, USA). The RRs were adjusted for the accidental extra freeze-thawing. The association between latent and lytic seroreactivity was measured by the Spearman rankorder correlation coefficient.

\section{RESULTS}

\section{Detection of IgG antibodies to HHV8}

Altogether, 277 out of 1960 (14\%) and 18 out of 1960 (1\%) serum samples were HHV8 positive in IFA for lytic antibodies and for the latent antibodies, respectively, with serum titres ranging from $1: 10$ to $\geqslant 1: 640$. The correlation between lytic and latent seroreactivity was $0.22(P=0.004)$ among cases and $0.19(P<0.001)$ among controls, respectively. There was no difference in HHV8 seroreactivity, considering males or females (Table 1). Among the different cohorts studied, we found a significantly higher HHV8 seroprevalence (IFA lytic was $27.9 \%$ and IFA latent was $1.7 \%$, respectively) among the samples from the ATBC Study (a Finnish cohort consisting only of men, all heavy smokers).

In all, 94 serum samples from MM cases and 282 from the controls, randomly selected, were also assessed for HHV8 DNA using a quantitative real-time PCR assay. Viral DNA was undetectable in all these samples tested and the other samples in the study were therefore not tested for HHV8 DNA.

The RRs of developing MM in case of HHV8 seropositivity were $0.8(95 \% \mathrm{CI}=0.5-1.1)$ and $0.6(95 \% \mathrm{CI}=1.0-2.7)$, respectively, for the presence of lytic and latent HHV-8 antibodies (Table 1); no differences were observed when the different serum banks were evaluated separately (Table 1 ).

To investigate whether the presence of as yet undiagnosed MM may have affected the results, we also analysed the data with the samples taken less than 2 years before diagnosis of MM was excluded, as well as by dichotimising the study into case-control sets with shorter or longer lag between enrolment and diagnosis. There were no noteworthy differences in results depending on lag (Table 2).

\section{DISCUSSION}

The prospective biobank-based study design, when used in countries with complete nationwide case ascertainment, minimises most of the epidemiological sources of bias. For example, reverse causality biases are not likely to occur with the long follow-up times between blood draw and diagnosis of cancer, and selection 
Table I RR of developing MM among subjects seropositive for HHV-8

\begin{tabular}{|c|c|c|c|c|}
\hline & MM on follow-up & Healthy on follow-up & $\mathbf{R R}$ & $95 \% \mathrm{Cl}$ \\
\hline \multicolumn{5}{|l|}{ IFA lytic } \\
\hline No & 290 & 1393 & 1 & \\
\hline Yes & 39 & 238 & 0.8 & $(0.5-1.1)$ \\
\hline \multicolumn{5}{|l|}{ IFA latent } \\
\hline No & 327 & 1615 & 1 & \\
\hline Yes & 2 & 16 & 0.6 & $(0.1-2.7)$ \\
\hline \multicolumn{5}{|l|}{ Females } \\
\hline \multicolumn{5}{|c|}{ IFA lytic } \\
\hline No & 106 & 544 & I & \\
\hline Yes & 18 & 75 & 1.2 & $(0.7-2.2)$ \\
\hline \multicolumn{5}{|c|}{ IFA latent } \\
\hline No & 123 & 611 & 1 & \\
\hline Yes & । & 8 & 0.6 & $(0.0-4.7)$ \\
\hline \multicolumn{5}{|l|}{ Males } \\
\hline \multicolumn{5}{|l|}{ IFA lytic } \\
\hline No & 84 & 849 & 1 & \\
\hline Yes & 21 & 163 & 0.6 & $(0.3-1.0)$ \\
\hline \multicolumn{5}{|c|}{ IFA latent } \\
\hline No & 204 & 1004 & 1 & \\
\hline Yes & 1 & 8 & 0.6 & $(0.0-4.7)$ \\
\hline \multicolumn{5}{|l|}{ FMC } \\
\hline \multicolumn{5}{|c|}{ IFA lytic } \\
\hline No & 29 & 131 & 1 & \\
\hline Yes & 2 & 23 & 0.4 & $(0.0-1.7)$ \\
\hline \multicolumn{5}{|c|}{ IFA latent } \\
\hline No & 31 & 152 & I & \\
\hline Yes & 0 & 2 & $0^{\mathrm{a}}$ & $(0-27)$ \\
\hline \multirow{2}{*}{\multicolumn{5}{|c|}{$\begin{array}{l}\text { HHS } \\
\text { IFA Iytic }\end{array}$}} \\
\hline & & & & \\
\hline No & 16 & 80 & 1 & \\
\hline Yes & 4 & 20 & 1.0 & $(0.2-3.7)$ \\
\hline \multicolumn{5}{|c|}{ IFA latent } \\
\hline No & 20 & 99 & 1 & \\
\hline Yes & 0 & । & $0^{b}$ & $(0-190)$ \\
\hline \multicolumn{5}{|c|}{ ATBC } \\
\hline \multicolumn{5}{|c|}{ IFA lytic } \\
\hline No & 25 & 104 & I & \\
\hline Yes & 7 & 43 & 0.7 & $(0.2-1.9)$ \\
\hline \multicolumn{5}{|c|}{ IFA latent } \\
\hline No & 31 & 145 & 1 & \\
\hline Yes & 1 & 2 & 2.5 & $(0.0-4.8)$ \\
\hline \multicolumn{5}{|l|}{ JANUS } \\
\hline \multicolumn{5}{|c|}{ IFA lytic } \\
\hline No & 183 & 904 & I & \\
\hline Yes & 20 & 111 & 0.9 & $(0.5-1.5)$ \\
\hline \multicolumn{5}{|c|}{ IFA latent } \\
\hline No & 202 & 1006 & 1 & \\
\hline Yes & 1 & 9 & 0.6 & $(0.0-4.0)$ \\
\hline Umeå & & & & \\
\hline IFA lytic & & & & \\
\hline No & 37 & 174 & I & \\
\hline Yes & 6 & 41 & 0.7 & $(0.2-1.8)$ \\
\hline IFA late & & & & \\
\hline No & 43 & 213 & 1 & \\
\hline Yes & 0 & 2 & $0^{\mathrm{a}}$ & $(0-27)$ \\
\hline
\end{tabular}

$\mathrm{RR}=$ relative risk: $\mathrm{MM}=$ multiple myeloma: $\mathrm{Cl}=$ confidence interval; IFA = immunofluorescence assay; FMC = Finnish Maternity Cohort; HHS = Helsinki Heart Study; Umeå $=$ The Northern Sweden Health and Disease Study; ATBC $=$ Alpha Tocopherol Beta Carotene prevention study; Janus $=$ The Janus biobank; Method: exact conditional logistic regression, adjustment for accidental freeze-thawing. ${ }^{a}$ Median unbiased estimate $=2.1$. ${ }^{b}$ Median unbiased estimate $=5.0$.
Table 2 RR of developing multiple myeloma by lag between sampling and diagnosis

\begin{tabular}{|c|c|c|c|c|}
\hline & MM on follow-up & Healthy on follow-up & $\mathbf{R R}$ & $95 \% \mathrm{Cl}$ \\
\hline \multicolumn{5}{|c|}{ Cases with lag > 24 months: } \\
\hline \multicolumn{5}{|c|}{ IFA lytic } \\
\hline No & 267 & 1288 & 1 & \\
\hline Yes & 37 & 221 & 0.8 & $(0.5-1.2)$ \\
\hline \multicolumn{5}{|c|}{ IFA latent } \\
\hline No & 302 & 1498 & 1 & \\
\hline Yes & 2 & 11 & 0.9 & $(0.1-4.2)$ \\
\hline \multicolumn{5}{|c|}{ Cases with < median lag (121 months) } \\
\hline \multicolumn{5}{|c|}{ IFA lytic } \\
\hline No & 144 & 668 & 1 & \\
\hline Yes & 20 & 143 & 0.6 & $(0.4-1.1)$ \\
\hline \multicolumn{5}{|c|}{ IFA latent } \\
\hline No & 163 & 798 & 1 & \\
\hline Yes & I & 13 & 0.4 & $(0.0-2.6)$ \\
\hline \multicolumn{5}{|c|}{ Cases with at least median lag (121 months) } \\
\hline \multicolumn{5}{|c|}{ IFA lytic } \\
\hline No & 146 & 725 & 1 & \\
\hline Yes & 19 & 95 & 1.0 & $(0.5-1.7)$ \\
\hline \multicolumn{5}{|c|}{ IFA latent } \\
\hline No & 164 & 817 & 1 & \\
\hline Yes & i & 3 & 1.7 & $(0.0-2.1)$ \\
\hline
\end{tabular}

biases due to incomplete attendance rate or inadequate study base definition are also unlikely.

We evaluated whether HHV8 infection was associated with an increased risk for MM, using the same prospective biobank-based study design and analyses as in our previous study that had found a nonsignificant tendency of association. We found no evidence of increased risk of MM associated with HHV8 seropositivity. As our current study is by far the largest ever prospective study on MM, the data suggest that HHV-8 is not associated with risk of MM. This conclusion is in line with several serological studies largely performed on different MM populations (Cottoni and Uccini, 1997; Mackenzie et al, 1997; Marcelin et al, 1997; Masood et al, 1997; Whitby et al, 1997; Olsen et al, 1998). The single study that found HHV 8 antibodies to be common among MM patients (Gao et al, 1998) used a sensitive immunoblotting method for detection of antibodies against the recombinant minor capsid antigen and latent nuclear antigen of HHV8. The present study did not use immunoblotting for measuring HHV8 antibodies, because our previous prospective study of $\mathrm{MM}$ did include immunoblotting against the viral antigens ORF65, ORF73 and ORFK8.1A, but found no association (Tedeschi et al, 2001a). The possibility that lack of association of the serological response to HHV8 and MM risk patients may reflect the relatively immunodeficient state typically associated with this malignancy is not likely, as the samples were taken up to 25 years before diagnosis of MM. The lack of association could conceivably be explained if $\mathrm{MM}$ is associated with a specific immune defect that prevents the generation of serologic responses to HHV8 or if it is associated with a unique strain of HHV8 that has a different immunogenic profile compared to the HHV8 strains found in KS (Berenson et al, 2000). However, in a recent study (Zhu et al, 2002), DNA sequences of three antigenic regions (ORF65, ORF73 and ORFK8.1) and the transforming hypervariable K1 ORF of HHV8 
were analysed in fresh bone marrow cells, bone-marrow-derived dendritic cells and bone marrow stromal cells, and were shown to be present in MM patients and normal individuals at similar frequencies.

In summary, the tendency for association between HHV-8 and MM in our previous smaller study could not be confirmed and our results provide evidence against an involvement of HHV8 in MM development.

\section{REFERENCES}

Ablashi DV, Chatlynne L, Thomas D, Bourboulia D, Rettig MB, Vescio RA, Viza D, Gill P, Kyle RA, Berenson JR, Whitman JE (2000) Lack of serologic association of human herpesvirus-8 (KSHV) in patients with monoclonal gammopathy of undetermined significance with and without progression to multiple myeloma. Blood 96(6): 2304-2306

ATBC Cancer Prevention Study Group (1994) The effect of vitamin E and beta carotene on the incidence of lung cancer and other cancers in male smokers. N Engl J Med 330(15): 1029-1035

Beksac M, Ma M, Akyerli C, DerDanielian M, Zhang L, Liu J, Arat M, Konuk N, Koc H, Ozcelik T, Vescio R, Berenson JR (2001) Frequent demonstration of human herpesvirus 8 (HHV-8) in bone marrow biopsy samples from Turkish patients with multiple myeloma (MM). Leukemia 15(8): $1268-1273$

Berenson JR, Sjak-Shie NN, Vescio RA (2000) The role of human and viral cytokines in the pathogenesis of multiple myeloma. Semin Cancer Biol 10(5): $383-391$

Bouscary D, Dupin N, Fichelson S, Grandadam M, Fontenay-Roupie M, Marcelin AG, Blanche P, Picard F, Freyssinier JM, Ravaud P, Dreyfus F, Calvez V (1998) Lack of evidence of an association between HHV-8 and multiple myeloma. Leukemia 12(11): 1840 - 1841

Cottoni F, Uccini S (1997) Kaposi's sarcoma-associated herpesvirus infection and multiple myeloma. Science 278(5345): 1972

Enbom M, Strand A, Falk KI, Linde A (2001) Detection of Epstein-Barr virus, but not human herpesvirus 8 , DNA in cervical secretions from Swedish women by real-time polymerase chain reaction. Sex Transm Dis 28(5): $300-306$

Gao SJ, Alsina M, Deng JH, Harrison CR, Montalvo EA, Leach CT, Roodman GD, Jenson HB (1998) Antibodies to Kaposi's sarcomaassociated herpesvirus (human herpesvirus 8 ) in patients with multiple myeloma. J Infect Dis 178(3): 846-849

Heid CA, Stevens J, Livak KJ, Williams PM (1996) Real time quantitative PCR. Genome Res 6(10): 986-994

Hermouet S, Sutton CA, Rose TM, Greenblatt RJ, Corre I, Garand R, Neves AM, Bataille R, Casey JW (2003) Qualitative and quantitative analysis of human herpesviruses in chronic and acute B cell lymphocytic leukemia and in multiple myeloma. Leukemia 17(1): 185-195

Kibur M, af Geijerstamm V, Pukkala E, Koskela P, Luostarinen T, Paavonen J, Schiller J, Wang Z, Dillner J, Lehtinen M (2000) Attack rates of human papillomavirus type 16 and cervical neoplasia in primiparous women and field trial designs for HPV16 vaccination. Sex Transm Infect 76(1): $13-17$

Lennette ET, Blackbourn DJ, Levy JA (1996) Antibodies to human herpesvirus type 8 in the general population and in Kaposi's sarcoma patients. Lancet 348(9031): $858-861$

\section{ACKNOWLEDGEMENTS}

This work was supported by the concerted action of Evaluation of the Role of Infections in Cancer using Biological Specimen Banks of the fifth framework program of the European Union and by the Swedish Cancer Society. This is publication number 32 from the Nordic Biological Specimen Banks working group on Cancer Causes and Control.
MacKenzie J, Sheldon J, Morgan G, Cook G, Schulz TF, Jarrett RF (1997) HHV-8 and multiple myeloma in the UK. Lancet 350(9085): $1144-1145$

Marcelin AG, Dupin N, Bouscary D, Bossi P, Cacoub P, Ravaud P, Calvez V (1997) HHV-8 and multiple myeloma in France. Lancet 350(9085): 1144 Masood R, Zheng T, Tupule A, Arora N, Chatlynne L, Handy M, Whitman Jr J (1997) Kaposi's sarcoma-associated herpesvirus infection and multiple myeloma. Science 278(5345): 1970-1971

Olsen SJ, Tarte K, Sherman W, Hale EE, Weisse MT, Orazi A, Klein B, Chang Y (1998) Evidence against KSHV infection in the pathogenesis of multiple myeloma. Virus Res 57(2): 197-202

Parravicini C, Lauri E, Baldini L, Neri A, Poli F, Sirchia G, Moroni M, Galli M, Corbellino M (1997) Kaposi's sarcoma-associated herpesvirus infection and multiple myeloma. Science 278(5345): 1969-1970

Patel M, Mahlangu J, Patel J, Stevens G, Stevens W, Allard U, Mendelow B (2001) Kaposi sarcoma-associated herpesvirus/human herpesvirus 8 and multiple myeloma in South Africa. Diagn Mol Pathol 10(2): 95-99

Perna AM, Viviano E, Iannitto E, Marceno R, Romano N (1998) No association between human herpesvirus type 8 infection and multiple myeloma. J Natl Cancer Inst 90(13): 1013-1014

Rettig MB, Ma HJ, Vescio RA, Pold M, Schiller G, Belson D, Savage A, Nishikubo C, Wu C, Fraser J, Said JW, Berenson JR (1997) Kaposi's sarcoma-associated herpesvirus infection of bone marrow dendritic cells from multiple myeloma patients. Science 276(5320): $1851-1854$

Santarelli R, Angeloni A, Farina A, Gonnella R, Gentile G, Martino P, Petrucci MT, Mandelli F, Frati L, Faggioni A (1998) Lack of serologic association between human herpesvirus- 8 infection and multiple myeloma and monoclonal gammopathies of undetermined significance. I Natl Cancer Inst 90(10): 781-782

Tedeschi R, Enbom M, Bidoli E, Linde A, De Paoli P, Dillner J (2001a) Viral load of human herpesvirus 8 in peripheral blood of human immunodeficiency virus-infected patients with Kaposi's sarcoma. J Clin Microbiol 39(12): $4269-4273$

Tedeschi R, Kvarnung M, Knekt P, Schulz TF, Szekely L, De Paoli PD, Aromaa A, Teppo L, Dillner J (2001b) A prospective seroepidemiological study of human herpesvirus- 8 infection and the risk of multiple myeloma. Br J Cancer 84(1): $122-125$

Whitby D, Boshoff C, Luppi M, Torelli G (1997) Kaposi's sarcomaassociated herpesvirus infection and multiple myeloma. Science 278(5345): 1971 - 1972

Zhu YX, Li ZH, Voralia M, Stewart AK (2002) Antigenic open reading frames from $\mathrm{HHV}-8$ are present in multiple myeloma patients and normal individuals at similar frequency. Leuk Lymphoma 43(2): $369-375$ 